\title{
EL CAMBIO DEL PARADIGMA RELIGIOSO: LUCRECIO Y LA CRÍTICA A LA RELIGIÓN COMO INSTRUMENTO DE PODER.
}

\author{
Ramón ROMÁN ALCALÁ \\ Dpto. de Filosofía \\ Universidad de Cóndoba
}

Se suele reconocer que el pensamiento epicúreo no es una instrucción sino una actividad que, por medio de reflexiones y razones intenta proporcionar una vida dichosa. Para ello, y, prioritariamente, el hombre debe excluir de su vida ciertos temores de carácter religioso: el temor a los dioses y a la muerte. No pretendió Lucrecio negar a los dioses en cuanto elementos del mundo, más bien intentó demostrar que estas divinidades, inútiles y abarcadas por su sistema, no intervenían ni en la libertad ni en la felicidad de los humanos. El intento de desarticular la esencia falsa de la religión le llevó a criticar los falaces supersticiones que impiden al hombre ser feliz. La consecución de este arquetipo no sólo asegura al individuo su independencia y libertad, sino que anula las perturbaciones del espíritu, provocadas por estos errores. La ética lucreciana se dirige, a través de todos sus mecanismos, al fin esencial del ser humano, la común idea epicúrea de la búsqueda del placer, creando así un nuevo modelo religioso y humano.

\section{Origen del culto a los dioses}

El desarrollo histórico de las concepciones religiosas, nos lleva siempre a la vinculación entre los problemas ontológicos -existencia o naturaleza de la divinidad- y los éticos o morales, que se refieren a las fuentes de las concepciones humanas sobre los

Éndoxa: Series Filosóficas, $n^{\circ} 7,1996$, UNED, Madrid:

Ramón Román Alcalá: El cambio del paradigma religioso: Lucrecio y la crítica a la religión como instrumento de poder.

pp. 115-133. 
dioses, en su influencia sobre la vida de los mortales, y a los motivos por los cuales creemos que vigilan las acciones humanas.

En Grecia, desde que el hombre creyó en la existencia de los dioses, estuvo persuadido de que influían en su destino, lo cual generaba una continua inquietud al quedar los asuntos humanos en manos divinas. La creencia en esta superstición originaba que para una afinidad de gente, como apunta Festugière, la religión se convertía en un grave peso sobre el alma y en una servidumbre ${ }^{1}$.

Lucrecio pretendió eliminar el miedo a la divinidad, demostrando que los dioses no han intervenido en la historia del mundo, ya que su intervención sería contradictoria con la misma esencia del ser divino. Se revuelve así contra la tiranía de la religión. La crítica de Lucrecio no se dirigirá exclusivamente, ni siquiera esencialmente, contra la superstición popular ${ }^{2}$, sino que su objeto fue principalmente la religión del estado, en cuanto sostenedora y promotora de las supersticiones; sus ataques encontraron en las circunstancias de su tiempo un incentivo particular.

La teoría según la cual la religión era una invención política había sido expresada en Grecia mucho antes de la época de Epicuro. Isócrates, contemporáneo de Platón, conoció bien este concepto a cerca de las ideas religiosas ${ }^{3}$; pero fue Critias uno de los "Treinta Tiranos" -tal como relata Sexto ${ }^{4}$ - quien frecuentando la compañía de los ateos lo desarrolló, encontrando que el origen de la religión se articulaba en el marco del desarrollo de la cultura:

«En los antiguos tiempos la vida de los hombres estaba exenta de todo orden e igual a la del animal: dominaba la fuerza, y ni el bueno hallaba premio ni castigo el soberbio.

${ }^{1}$ Festugiere, J. A., Epicure et ses dieux, Paris, 1946, reed. 1986, p. 76; existe traducción española Epicuro y sus dioses, Buenos Aires, 1960.

${ }^{2}$ Lucrecio no distingue entre religio y superstitio, más bien las identifica; cfr. Lucrecio, De rerum natura, I, 62-67 (a partir de ahora Lucrecio, 1...).

${ }^{3}$ Isócrates, Busiris, 34, 37.

${ }^{4}$ Cfr. Sexto, M., IX, 49 y ss. 
Luego, según me parece, se crearon las leyes con castigo, para que sobre todos domine igual el derecho (...) la ley impedía al hombre cometer violencia a la luz, el crimen se sumió y reptó en la oscuridad. Entonces, me parece, un hombre astuto y prudente inventó para los mortales el temor a los dioses. Tenía que haber un terror para el malo, aunque la acción, la palabra y el pensamiento fueran secretos. Así pues introdujo aquel hombre la religión"s.

Desde este punto de vista, la religión es, pues, un invento engañoso y arbitrario de un hombre astuto; invento, por otro lado, necesario para reforzar el papel de la ley. Pronto se dará una alianza inalterable a través de los tiempos, entre la ley y la religión.De ahí, que Lucrecio refuerce su posición critica ante la identidad que se da entre religión y Estado. Está claro que la crítica de Lucrecio iba dirigida contra la religión que caía sobre los mortales con su horrible aspecto; también contra los cultos, innecesarios y superfluos, de interés sólo político. La validez de la religión como instrumento de dominación está presente en todas las conciencias de la clase gobernante romana; su utilidad pública está constantemente demostrada en los testimonios de la época. Polibio en sus Historias define magistralmente esta relación tan «sombría»:

«Pero a mí me parece que la auténtica superioridad del Estado romano hace referencia a la concepción de los dioses (...) dado que la multitud es inconstante y desenfrenada en sus ilícitos deseos, fácil a la ira, violenta e impetuosa, no queda más remedio que tenerla sujeta con misteriosos terrores".

5 Para este poema Sexto es la única autoridad Sexto, Pròs Mathèmatikoús, IX, 54, (a partir de ahora M.,) obsérvese como aparece en él la vieja idea de la compensación por medio del castigo. Lo importante de la justicia no es evitar el delito, sino castigar al culpable una vez que aquél se ha cometido. La justicia no teme el delito, lo espera, lo que no tolera es la impunidad.

6 Polibio, Historias, VI, 56, 2. 
Desde entonces -dice Lucrecio- el temor al castigo ha envenenado los goces de la vida. El hombre se ha dejado seducir por la religio, logra la organización de la vida colectiva mediante el hallazgo de la ley y entona un solemne canto de sumisión voluntaria de la individualidad y la libertad al bien común. No es difícil entender por qué entre las grandes naciones la idea de divinidad se divulgara tan fácilmente, los cultos llenaran de templos las ciudades y aparecieran rituales, en los que el terror religioso estaba muy enraizado. Lucrecio no podía pasar por alto que las leyes romanas eran humanas, pero - y esto es lo más importante- también divinas. El efecto negativo de la ley estaría en la ofensa al supremo garante, la divinidad. Es significativo el lugar, el origen de la religio, dentro de la evolución de la humanidad. Existe una relación consciente entre la aparición de la ley y la de la religión.

Lucrecio observa la utilización que el poder político de Roma hace de la religión: como fundamento para su poder y como aglutinante de la conducta social de las masas. El poder religioso podía controlar, mejor que el poder político a la población; ésta acataría cualquiera de los intereses ofrecidos, al ser deseados por la divinidad, truco que ha sido usado en más de una ocasión en la historia del mundo. La desobediencia política entrañaba un insulto a los dioses, más que a los mismos gobernantes (que, en ocasiones eran divinizados). Cicerón, representante del mundo conservador se manifiesta repetidas veces partidario de la conexión entre lo sagrado y lo civil ${ }^{7}$, ya que, convencido del engaño de las adivinaciones, afirma la necesidad de salvaguardar la autoridad de los «augures» por su utilidad política ${ }^{8}$. Así, Lucrecio luchará más contra la religión organizada de la aristocracia que contra las supersticiones populares:

${ }^{7}$ Cfr. Ciceron, De finibus., I, 1, 16.
${ }^{8}$ Véase también De Leg., Il, 12-13. 
"Un temor me acomete aquí: no vayas a creer que te inicias en los principios de una ciencia impia y que entras por un camino sacrílego. Al contrario, las más de las veces es ella, la religión, que ha engendrado crímenes e impiedades. Asi en Aúlide, los caudillos elegidos de los dánaos, flor de los héroes, torpemente mancillaron con la sangre de Ifianasa el altar de la Virgen de las Encrucijadas (...) a fin de asegurar a la flota partida feliz y propicia (exitus ut classi felix fautusque daretur). ¡A tantos crímenes pudo inducir la Religión!»?.

En este texto Lucrecio apunta a los jefes supremos de los Dánaos, ellos son el ídolo polémico y sutil, la crítica no va dirigida contra la multitud ignorante sino contra el acto oficial de Estado mediante el cual se intenta asegurar el éxito de un fin político ${ }^{10}$. Es la fórmula para elevar la moral. Ciertamente, no podemos saber hasta qué punto, la antirreligiosidad de Lucrecio tiene como base las irregularidades religiosas romanas, este es el campo de batalla de múltiples interpretaciones de la obra lucreciana. Autores como Altheim, Macaulay, Patin o Sinker aceptan la teoría de que Lucrecio exageraba los horrores y errores de la religión de su época, al ser más un crítico de los libros que un crítico social; más acertados a mi entender los del otro bando, Mommsem, Martha o Platt $^{11}$ piensan que fueron las circunstancias de su tiempo, las supersticiones políticamente utilizadas por el poder las que obligan a Lucrecio a escribir contra los vicios de su tiempo. Es evidente, que las clases dirigentes, la nobleza (en términos generales) consideraría exageradas las críticas o hasta cómico el énfasis del poeta, pero esa misma nobleza no dudaba en utilizar los mismos

${ }^{9}$ Lucrecio, I, 80-101. Creo que no es necesario preguntarse por qué el Senado expulsó de Roma a los filósofos epicúreos.

${ }^{10}$ De esta misma opinión en Farrington, B., Ciencia y política en el mundo antiguo, Madrid, 1965, p. 188.

${ }^{11}$ Cfr. mi «Boletín bibliográfico sobre el De rerum natura de Lucrecio», Revista Dokos, 1, 1983, pp. 153-180. 
miedos o terrores para conseguir cualquier efecto teatral sobre las masas siempre impresionables. $Y$ esos errores, utilizados por la religión, no son inconscientes, sino que se difundieron como el método más eficaz para abatir todo posible espíritu de libertad.

¿Capacita lo anterior para señalar a Lucrecio como uno de los grandes ateos romanos? Creo que no. La deliberada intención de Lucrecio es enfrentar el espíritu de la verdadera (concepto religioso epicúreo) y el de la falsa religión. Epicuro enseña que la fe en los dioses antropomorfos de la tradición griega debía ser aceptada ${ }^{12}$. Como también debe ser aceptada la validez de la interpretación alegórico-moral del mito, siempre que se cuide con no turbar el espíritu con la superstición. "Ahora bien -dice Lucrecio- si alguien decide llamar al mar Neptuno, a las mieses Ceres, y prefiere usar el nombre de Baco en vez de designar el vino con su vocablo propio, concedámosle decir que el orbe terráqueo es la madre de los dioses, con tal de que en realidad se guarde de contaminar su espiritu con una torpe superstición ${ }^{13}$. Estamos frente a una casi milagrosa confirmación religiosa, que también puede ser interpretada, en el fondo, como una poética indiferencia. Lucrecio enriquece el epicureísmo adaptándolo a su tiempo: cambia su forma para salvaguardar su contenido. Lucrecio intenta contraponer una verdadera filosofía que explique racionalmente la naturaleza del alma, el irracional miedo a la muerte y la naturaleza de los dioses: un nuevo culto, una nueva piedad que consista en la contemplación serena de todo lo existente:

«No consiste la piedad en dejarse ver a cada instante, velada la cabeza, vuelto hacia una piedra, ni en acercarse a todos los altares, ni en tenderse postrado - por el suelo-y extender las palmas hacia los santuarios divinos (...) sino más bien en ser capaz de mirarlo todo con mente serena ${ }^{14}$.

\footnotetext{
12 Cfr. Festugière, J.A., op. cit., pp. 93-100.

${ }^{13}$ Lucrecio, II, 654-659.

14 Lucrecio, V, 1119-1204.
} 
El propósito de Lucrecio es luchar contra la consciente conservación de las principales supersticiones populares, por razones de conveniencia práctica o política. Farrington ${ }^{15}$ añade que la tensión se desplaza desde la superstición popular hacia la religión de Estado en donde esa superstición juega un papel muy sofisticado e ideológico. Pero entendemos que en el De rerum natura, esa intención viene acompañada por un intento educativo de crítica contra la religión, contra todo lo que se mantiene por encima de la estricta observación, por encima de lo que existe. La naturaleza de las cosas hace que obviemos los pilares fundamentales religiosos que, no olvidemos, son todos ellos sobrenaturales. Es la natura rerum la que refutará y sustituirá las explicaciones «no naturales», fuente de tinieblas y de angustias, por una explicación que pretende ser estrictamente "natural»" Asi refuerza Lucrecio su explicación natural racional y adulta, frente a las explicaciones religiosas infantiles y supersticiosas, «pues tal como los niños tiemblan y de todo se espantan en las ciegas tinieblas, asi a menudo nosotros en la luz tememos cosas... Este terror, pues, y estas tinieblas del espíritu, necesario es que las disipen no los rayos del sol ni los lúcidos dardos del día, sino la contemplación de la naturaleza y de la ciencian ${ }^{17}$.

En consecuencia, el efecto que la filosofía de Lucrecio tuvo en su tiempo fue el oponerse la supertición de los romanos, ayudando a los hombres a sobreponerse a ella ${ }^{18}$. La filosofía epicúrea da al traste con todas aquellas creencias infundadas en torno al vuelo de las aves, a la significación de la liebre que cruzaba el camino, a la inspección de las entrañas de los animales, a la alegría o la tristeza de las gallinas, dejando que prevaleciese como verdad solamente aquello que proclamaba la sensación; de ella arrancaban las repre-

\footnotetext{
15 Vid., Farrington, B., Op. cit., pp. 187-189.

${ }^{16} \mathrm{Cfr}$. Rosset, Cl., Lógica de lo peor (elementos para una filosofía trágica), Barcelona, 1976, p. 154.

17 Lucrecio, II, 55-61.

${ }^{18}$ Cfr. Cicerón, De natura deorum, I, 20.
} 
sentaciones que había de conducir a la negación de lo suprasensible.

Los primeros gobernantes romanos hablaban como padres y cónsules desde los papeles que desempeñaban; si empleaban la religión para manipular a los plebeyos, se trataba al menos de una religión que compartían. Pero muy pronto esto deja de ser así. Cuando la religión se convierte en un instrumento de manipulación, los miembros de las clases media y superior no pueden compartir las creencias que emplean con motivos políticos. Necesitan creencias que sean racionales de acuerdo con sus propias normas y justifiquen lo que la romanitas misma justificó una vez. Estas necesidades serán satisfechas por el estoicismo y en menor medida por el epicureísmo. Séneca y Marco Aurelio ejemplifican el aspecto público del estoicismo; Lucrecio, la cualidad liberadora del epicureísmo. Ambas doctrinas tienen una función esencial en un mundo en el que importa más la evasión del dolor que la búsqueda del placer. Cada una tiene en el ámbito romano una función que la religión oficial no llegó a cumplir. Ambas colocan al individuo en el contexto de un cosmos, no en el de una comunidad local; incluso - como ocurre en el epicureísmo- a costa de los propios dioses.

\section{Los dioses no rigen el mundo.}

Los epicúreos creían realmente en la existencia de las dioses, por la misma razón que creían en la existencia de otros objetos materiales; sólo era erróneo a sus ojos - como bien señaló Lucrecio- mezclar a los dioses con los procesos normales de la naturaleza. Es igualmente erróneo suponer que los dioses mantienen y controlan, con su benévolo poder, los avatares cotidianos de la vida humana. El miedo no es obra de los dioses, pero las falsas ideas que de ellos nos hacemos crean el miedo. Este oscuro y cobarde temor es el responsable de la difusión de la falsa religión o superstición; es el causante, en definitiva, de que 
«Las ciudades se llenaran de altares y se establecieran los solemnes ritos que ahora florecen en las grandes ocasiones en lugares famosos; de donde aun hoy un religioso terror está enraizado en los hombres, el cual les hace levantar por todo el orbe de la tierra nuevos santuarios a los dioses y les impulsa a llenarlos en los días festivos ${ }^{19}$.

El sistema natural epicureísta tolera a los dioses, aun no siendo necesarios. Lucrecio no va contra la opinión que tenemos de los dioses como imágenes prestigiosas, a las que atribuimos vida y eternidad, sino -como dice Boyancé- «contra las falsas inferencias que ligan esta idea a los fenómenos meteorológicos, suscitando en nosotros el terror ${ }^{20}$. Ciertamente que el sistema lucreciano hubiese exigido una mayor valentia con respecto al intento de racionalizar la religión, que es lo que pretendía; sin embargo, haber llevado la crítica más allá hubiese exigido tal impiedad, que no podía y no estaba dispuesto a soportar. Así pues, sosteniendo la existencia real de los dioses, enseñaron que era un error vincular las potencias de la naturaleza con la divinidad, para evitarlo tenían que fortalecer su espíritu con una filosofía de la naturaleza acorde con este modelo.

Para Epicuro, todo es explicado por el mecanismo propio de los átomos en el seno del vacío. De esa forma hasta los dioses serían compuestos atómicos; no estarían, sin embargo, afectados de mortalidad, ya que las emanaciones que emiten se van supliendo mediante constantes aflujos de átomos, de modo que su forma permanece inmutable y continuamente renovada ${ }^{21}$. Así, eternamente felices, disfrutando de la paz más profunda, ajenos al devenir, resultan invulnerables a las acciones de los hombres. Los dioses en contrapartida nunca han intervenido en la vida humana;

19 Lucrecio, V, 1163-1168.

20 Boyancé, P., Lucrèce sa vie, son oeuvre, avec un exposé de sa philosophie, Paris, 1964, p. 7.

${ }^{21}$ Cfr. Lucrecio, V, 146-148 y 1175-1182. 
tampoco pueden hacerlo ahora. De esta forma, la evidente crítica antiprovidencialista de los epicúreos es resaltada por Lucrecio mediante una idea nueva y original: la constante referencia a las imperfecciones de la naturaleza y a los males del mundo. Lucrecio prefiere enfrentar al hombre con un mundo hostil antes de dejar una puerta abierta a la conversión de los dioses en tiranos, como habría ocurrido al aceptar la bondad del mundo ${ }^{22}$.

«Pues, aunque ignorara lo que son los átomos, la sola observación de los fenómenos celestes, corroborada por muchas otras razones, me daría ánimos para afirmar lo siguiente: el mundo no ha sido creado para nosotros por obra divina; tan grandes defectos lo afean ${ }^{23}$.

Lucrecio intentó extirpar esas creencias antiguas, que establecían que todo aquí abajo dependía de los dioses que se comportaban como seres personales, sujetos a pasiones y a los sentimientos de la misericordia, de la piedad y de la venganza. Tal opinión que dominaba el corazón de los hombres generaba un miedo incontrolado hacia lo desconocido. Los epicureistas intentan purificar los contenidos religiosos, observan -igual que los escépticos- todos los usos culturales-religiosos, pero divorciándolos de cualquiermiedo a la cólera divina o de beneficios materiales, como bien apunto Dodds, para ellos una religión presidida por el lema do ut des sería de la peor blasfemia ${ }^{24}$.

La revuelta del epicureísmo en general y de Lucrecio en particular no implica necesariamente el ateísmo ${ }^{25}$, más bien

\footnotetext{
162.

22 Cfr. Farrington, B., Mano y cerebro en la antigua Grecia, Madrid, 1974, pp. 160

23 Lucrecio, II, 177-181. La réplica va dirigida contra la tesis estoica de la adaptación de la naturaleza para satisfacer las necesidades del hombre, cfr. Cicerón, De netura deorum, II, 150, doctrina cuya fuente posiblemente se encuentra en Empédocles y Anaxágoras; vid, Aristóteles, Física, II, 8, 1986.

${ }^{24}$ Cfr. Dodds, E.R., Los griegos y lo irracional, Madrid, 1980, p. 225.

25 Puede perfilarse en Lucrecio tres niveles de relaciones frente a las redes de la
} 
conserva los dioses lejos del hombre, dotándolos de una perfecta indiferencia frente al mundo que ellos no han creado. Fraisse llega a decir que la supervivencia de estos dioses en un sistema antirreligioso (expresión un tanto exagerada) probaba de forma evidente que lo que cuenta no es la existencia de los dioses sino su providencia $^{26}$. Este análisis lleva en sí una enérgica e infatigable crítica de lo sagrado, que no tiene sentido más que en la relación que une a los hombres con lo divino. El deseo de Lucrecio no era negar la existencia de los dioses, al contrario, se trata de confirmar esta evidencia, por argumentos filosóficos; sobre todo de mostrar que estas divinidades inútiles en el sistema tienen un papel que desempeñar en la conquista de la sabiduría y la felicidad. La divinidad que es accesible a los humanos gracias a los simulacros que ella emite, debe ofrecer la imagen de una bondad y una belleza ideales cuya consecución en la práctica epicúrea nos lleve a la ataraxia. El hombre se entrega, paulatinamente, a su razón. Nadie se resigna a contemplar la vida; hay que entregarse fervorosamente a ella si queremos encontrar la felicidad. El esfuerzo demuestra precisamente lo más elevado del hombre. A través de la razón éste se afirma en su ser propio comprendiendo la naturaleza. Hasta Epicuro la ley, los dioses configuraban la realidad, a partir de él, el hombre debe buscar en sí mismo el principio de su destino, de su propia libertad. El epicureísmo intentó «instalar a los dioses en un lugar justo en su sistema del mundo y se puede decir que los reconcilia con los hombres»" ${ }^{27}$.

religión, frente a la superstición:

1) Comprende la postura de los ignorantes, que desconociendo las cosas ven los fenómenos naturales, los atribuyen a los dioses y caen en aberrantes supersticiones (Lucrecio, V, 1183-1187).

2) Aquellos quienes afirmando estar a salvo de toda superstición, incurren en ella en los momentos dificiles y en las circunstancias desgraciadas (III, 40-54).

3) La tranquilidad de espíritu del sabio, semejante a los dioses, inaccesible a las orientaciones de las falsas creencias (III, 319-322).

${ }^{26}$ Fraisse, S. "De Lucrèce à Camus ou les contradictions de la révolte», Reo. Esprit, 1959, (27), p. 438.

${ }^{27}$ Grimal, P., "Le poème de Lucrèce en son temps", Entretiens sur l'antiquité classique, Fondation Hardt, Vandoevres-Genève, 1978, p. 254. 


\section{El temor a la muerte.}

El temor a los dioses pieza clave en la ética epicúrea no aparece en Lucrecio aislado en la existencia humana. Esta flaqueza del individuo está estrechamente relacionada con el horror a la muerte, con el miedo a la ausencia de vida. La lucha del epicureísmo no concluyó asegurando al hombre su independencia y libertad frente al fatalismo divino; el esfuerzo más significativo se dirigió a la abolición de las perturbaciones del espíritu provocadas por el temor a la muerte.

La muerte es el término ineludible de la vida y no cabe la esperanza de rehuirla. Ocuparse de la muerte es también ocuparse de la vida en su límite; la muerte puede arrojar a la vida su sentido, como proceso retroproyectivo. La muerte aparece como eliminación de lo porvenir, destruye la existencia con lo que obliga al hombre a no aplazar la vida. El hombre, por tanto, dice Lucrecio, puede y debe sobreponerse a la muerte, rodearla de algún modo y hacerse con ella. La muerte desde esta perspectiva y utilizando una simbología rilkeana, sería un acto más del ser humano, el último acto de nuestra vida. Morir no sería más que completar la existencia, completar nuestra vida. Hay que rescatar la muerte para que no sea un episodio que perturbe nuestra mente, sino un acto más de nuestra vida mortal. La muerte es el final de todos nuestros anhelos, el fin de la sensación. Es un episodio de nuestra existencia que llega en el momento oportuno...cuando llega,

"¿qué inmoderado y funesto afán de vivir nos fuerza a temblar de este modo en tan dudosos peligros? El fin de la vida está, en verdad, fijado a los mortales, y nadie se escapa de comparecer ante la muerte ${ }^{28}$.

${ }^{28}$ Lucrecio, III, 1076-1080. 
Así, la primera tarea del hombre, una vez aceptada lo que significa la muerte, es acostumbrarse a sus consecuencias. La muerte nos despoja; es el temor a esta extrema pobreza lo que nos hace temerla como algo insoportable. Cuando un hombre cumple con la vida no teme a la muerte. Así, como dice el propio Lucrecio, no podemos alargando nuestra vida robar ni un momento siquiera a la muerte. Aferrarse a la existencia no es, pues, una victoria, sino una servidumbre: comienzo o límite son dos formas de sentir la vida.

Lucrecio analiza, exhaustivamente, los efectos de este falso temor, que ensombrece la vida evitando un goce placentero y limpio. De nuevo estamos ante la búsqueda del placer como fin esencial del hombre, búsqueda que se verá obstaculizada por esta creencia en la muerte, que domina al hombre y le impide gozar de la vida ${ }^{29}$. La idea de la muerte es, por tanto, lo que más abruma al hombre; los otros males: enfermedad, exilio, deshonra, le parecen, en comparación, bastante tolerables. Ninguno, por intenso que sea, suscita los mismos sentimientos y pasiones que la muerte. Este miedo mostraba plena vigencia en la Roma de Lucrecio. Quizá no un miedo que impidiese vivir, pero sí un miedo asumido, soterrado que carcomía cualquier posibilidad de rectificación religiosa. El error al aceptar las creencias religiosas llevaba fácilmente al miedo. Miedo que se veía reflejado en mitos y fabulaciones que servían para atormentar a los necios y espantar a los crédulos. Por ello, por confusión y temor se intentaba como equilibrio vital alcanzar en esta vida riqueza y poder innecesarios,

29 Este afán por anular el temor a la propia desaparición unido a unas demostraciones de esperanza en otra vida, no es propio ni exclusivo del epicureísmo; existen señales de esta idea en el pensamiento socrático-platónico; «Temer a la muerte no es otra cosa que creer ser sabio no siéndolo, pues es como creer saber lo que no se sabe; Nadie, en efecto, respecto a la muerte sabe si es para el hombre el mayor de todos los bienes y, sin embargo, la temen como si supieran con certeza que es el mayor de todos los males" Platón, Apologia de Sócrates, 29a, podemos ver también República, 608d; Fedro, 245c; Fedón, 66d; C.fr. también CICERON, De finibus, I, 55, la idea de una eternidad desgraciada es particularmente temida por el individuo; por último, Vid., EPICURO, Epistula ad Phitoclem: Diógenes Laercio, Vitae Philosophorum, X, 87 (a partir de ahora D.L.).). 
como garantía dilatoria de su muerte. Parece inevitable, entonces, encontrar en ella la raíz de los males combatidos por los epicúreos: ambición de poder y, más aun, necesidad de honores, que no son, como observa Boyancé y desarrolla Perret, tan agravados por ella (por la muerte) como nacidos de ella ${ }^{30}$.

Lucrecio va a establecer una relación curiosa, pero fundamental entre el miedo a la «moira» que encadena a los hombres y su sed de riqueza y codicia. Resulta incomprensible para Lucrecio la cuestión de la muerte si no va unida a las pasiones y sentimientos más mezquinos en el individuo. Esta frenética y precisa causalidad genera en el hombre los terrores estériles de la mortalidad. Lucrecio presenta un panorama ciertamente desesperanzador con respecto a las ambiciones humanas. «En fin -dice- la codicia y la ciega ambición de honores que fuerzan a los míseros hombres a violar las fronteras del derecho y a veces, haciéndose cómplices y servidores del crimen, a esforzarse dia y noche con empeñado trabajo para escalar el poder, tales llagas de la vida en no pequeña parte son alimentadas por el temor a la muerte ${ }^{31}$.

Si conseguimos, pues, desterrar esa inseguridad terrenal, ese miedo a la muerte habremos abolido parte de las agonias del género humano. Ciertamente, parece que el hombre necesita saciarse con un banquete de cosas en las que no encuentra satisfacción, pero que son reflejo de su miedo e inseguridad. Para el epicureísmo ese es el motivo profundo, urgente e imperativo que debe resolver la filosofía. El primer paso lo aporta el propio Lucrecio cuando justamente ataca las tópicas creencias que fuerzan al hombre al miedo a la muerte, «Pues el desprecio infamante y la amarga pobreza se cree comúnmente que son incompatibles con la dulzura y estabilidad de la vida, y parecen como un vivir permanente (Cunctarier) ante el umbral de la muerte ${ }^{32}$. Lucrecio

\footnotetext{
${ }^{30}$ Cfr. Boyancé, P., Lucrèce et l'épicurisme, Paris, 1962, pp. 146-147 y Perret, J. "L'amour de l'argent, l'ambitio et la crainte de la mort", dans Melánges A. Emout. Paris, 1940, pp. 277-284.

${ }^{31}$ Lucrecio, III, 59-64.

32 Lucrecio, 11I, 65-68; Valentí traduce el término "cunctarier" por "demora"
} 
cree que sólo se puede ser ambicioso o codicioso para huir de la miseria de la muerte. Dos aspectos contrarios van a desarrollarse en esta idea: estabilidad de la vida en la riqueza y los honores y destrucción de la misma en la indigencia y en la pobreza. Existe una suerte de dialéctica, resaltada por Lucrecio y otros autores entre el miedo a la muerte por una parte, y la ambición y la codicia por otra ${ }^{33}$, que atenazan al individuo evitando su felicidad, y así, dice Lucrecio, "los hombres quisieron hacerse ilustres y poderosos para sentar su fortuna en una sólida base y poder vivir plácidamente en la opulencia ${ }^{34}$.

Según la opinión de Perret, la relación de causa y efecto entre el miedo a la muerte y la miseria o el abatimiento encontraba su explicación en la situación política, tal como aparecía en Roma en el último siglo de la república. Es más, refuerza su parecer con las siguientes palabras «en una sociedad civilizada y un poco estable, no hay razón para que un hombre pobre y sin defensa se sienta por este hecho, amenzado por la muerte ${ }^{35}$. No era ésta, por supuesto, la realidad de la época de Lucrecio políticamente pujante, en la que ser temerosos, rico y despiadado eran los elementos necesarios para salvaguardar la existencia. Sin embargo, cabe hacer una objeción a esta interpretación, ya que podemos comprobar - y los hechos no lo prohíben-que en los períodos de disturbios los ricos y poderosos están, generalmente, más amenazados que los pobres y desgraciados. Desde el punto de vista de Perret esta visión sería inexacta, deformada por el espíritu aristocrático y moralista de los historiadores de la antigüedad. Lucrecio tiene él mismo una opinión sobre este particular, que quizá se le escapó a Perret. Volvamos de nuevo al pasaje V, 1120

\footnotetext{
hemos creído más conveniente utilizar la expresión "vivir permanentemente" que significa un retardo en un proceso que debia producirse. Cfr. Desmouliez, A., "Cupidité, ambition et crainte de la mort chez Lucrèce», Latomus, 1958, (17), p. 318.

${ }^{33}$ Cfr. Salustio, De Bell. Ius., 41, 6, 10.

34 Lucrecio, V, 1120-1123.

35 Perret, I., loc. cit., p. 281.
} 
y ss. citado más arriba. Una vez que el poeta ha evocado el deseo que tienen los hombres de encontrar la estabilidad de su vida en los honores y en la riqueza dice:

«Todo en vano, pues en la contienda para escalar la cima de honor llenaron de peligros el camino; y aun, si llegan a encumbrarse la envidia los derriba de un golpe como un rayo, y los precipita ignominiosamente en el Tártaro espantoso" ${ }^{36}$.

$\mathrm{Ni}$ aun los poderosos que alcanzan la riqueza están a salvo, pues su misma suerte los derriba sin compasión desde el alto lugar que ocupan a la fría tierra. Lucrecio denuncia la vanidad y, mismamente, lo absurdo de la ambición, no sólo para condenarla, sino también para oponerlas a la verdadera sabiduría cuyo conocimiento puede traer la "salvación». Más allá del juicio de Lucrecio, aparte de las afirmaciones teóricas de Epicuro ${ }^{37}$ o de los ejemplos que nos ha dado ${ }^{38}$, ¿no nos encontramos, en definitiva, en el fondo mismo de la doctrina y con sus imperativos mayores? Citémoslos de nuevo: ausencia de toda pasión, no participación en la vida pública, alejamiento de la multitud, búsqueda de la seguridad interior. Todas estas ideas son demasiado epicúreas como para encontrar alguna contradicción o vacilación, con respecto a ellas, en el pensamiento de Lucrecio. Se aparta, sin duda, de la ortodoxia epicúrea, más por su curiosidad y su espíritu de sabio que por desacuerdo con la doctrina ${ }^{39}$.

Hemos visto, hasta ahora, que Lucrecio aporta dos respuestas diferentes al problema, sin embargo, las dos concluyen originaria-

36 Lucrecio, V, 1122-1127.

37 Epicuro, Ratae Sententiae, VII; D.L., X, 140, "Algunos han querido hacerse famosos y admirados, creyendo que así conseguirian rodearse de seguridad frente a la gente..."; Cfr. XV: D.L., X, 144 y XXI: D.L., X, 146.

${ }^{38}$ Cfr. D.L., $X, 11$.

${ }^{39}$ Cfr. Bayet, J., "Études lucrétiennes (L'originalité de Lucrèce dans l'épicureisme; Lucrèce et le monde organique)", Cahiers du Collège Philosophique, GrenobleParis, 1948, pp. 57-138. 
mente en un sentimiento trágico, ya que la búsqueda de la seguridad en los honores y la riqueza es hacer prueba de idiotez y de inconsecuencia; huir de la sabiduría, según la moral epicúrea. Lucrecio muestra claramente que, aunque el hombre ha progresado desde un estado de barbarie a otro más civilizado, no es feliz. Así pues, los valores codiciados por los hombres de su tiempo serían la causa de los peores sufrimientos, pues en nada les aprovechan ${ }^{40}$. Lucrecio sitúa en el fondo del alma humana la creencia de la muerte, y en ese sentimiento el resorte de la ambición y la codicia. En el momento de afirmar la idea esencial de Lucrecio sustituye el pensamiento abstracto por la visión concreta que la convicción le impone. Llega más allá del epicureís$\mathrm{mo}^{41}$, ya que comienza por denunciar la locura de los hombres que, para encontrar la seguridad, se abandonan al egoísmo; aunque señala enseguida la vanidad y lo absurdo de esos esfuerzos, que no procuran más que peligros a los hombres 0 , mismamente, aceleran su muerte. Esta contradicción, esa relación que establece el epicureismo entre el fin que se impoen el hombre y el resultado que obtiene aparece en un texto preciso de Epicuro:

"Algunos han querido hacerse famosos y admirados, creyendo que así conseguirían rodearse de seguridad frente a la gente. De modo que si su vida es segura, consiguieran el bien de la naturaleza. Pero si no es segura se quedan sin el objetivo al que se sintieron impulsados desde el principio conforme a los propio de la naturaleza ${ }^{42}$

Toda la crítica coincide en presentar este texto como fuente del pensamiento de Lucrecio. Pero las diferencias en la expresión de

${ }^{40}$ Barbu, M.N.I., «La hiérarchie des valeurs humaines chez Lucrèce», Actes $d u$ VIII-Congrès, Association Guillaume Budé, Paris, 1969, p.368; Cfr, Borle, I.P., "Progrès ou déclin de l'humanité", Museum Helveticum, 1962, (19), pp. 163-176.

${ }^{41}$ Cfr. Pirelli, L., Lucrezio poeta dell'angoscia, Firenze, 1969, pp. 76-80.

42 Epicuro, Ratae Sententias, VII: D.L., X, 141. 
la idea son bastante nítidas como para permitir descubrir a través de ellas el método de Lucrecio y el trabajo de su espíritu. Epicuro propone en el texto antes mencionado una abstracción de la teoria y da una alternativa; Lucrecio, fiel a la doctrina, lógicamente cerrado en sus convicciones, más epicúreo que el propio Epicuro, no puede admitir ni concebir mínimamente que el hombre encuentre seguridad en el poder, ya que negaría el ideal de la sabiduría epicúrea. Sustituye la fría dialéctica por una demostración que prueba la fatalidad de los peligros a los que el hombre se somete en el seno del poder, acabando así con su vida tranquila, "los hombres quisieron hacerse ilustres y poderosos, para asentar su fortuna en una sólida base y poder vivir plácidamente en la opulencia; todo en vano ${ }^{43}$. De nuevo el poema aparece comprendido plenamente en su tiempo, Lucrecio hace clara referencia a los acontecimientos coetáneos y confirma, al contacto con la realidad, un pensamiento enraizado en la sociedad romana ${ }^{44}$.

Los pasajes que hemos visto revelan por una parte, fidelidad clara al pensamiento de Epicuro y, al mismo tiempo, voluntad de reflexión y análisis que descubre la verdad. Para la convicción de Lucrecio en sus afanes por el logro de la felicidad, quizá resultó más apremiante salvar el escollo de los temores del individuo ante lo inevitable de su propia disolución, que ante la idea de su rígido control por parte de la divinidad omnipresente. Así pues, sólo el conocimiento de la verdad mediante el estudio de la ciencia y la contemplación de la naturaleza pueden liberar al hombre de los tormentos que le acechan en su ignorancia, logrando, en conse-

\footnotetext{
43 Lucrecio, V, 1120-1130.

44 Lucrecio enlaza, denunciando la ambición y la codicia del poder de sus contemporáneos, con una tradición moral que se desarrolla en Roma, en particular, por ios historiadores, Cfr, Salustio, Cat., X: comparando las dos intenciones nos damos cuenta de la originalidad de Lucrecio. Salustio sin duda quiere hacer una obra pero su análisis de las consecuencias de la ambición y de la codicia queda limitada a una situación histórica. Lucrecio llega más lejos, sondea el alma humana y descubre, a través de las circunstancias que lo rodean, las causas psíquicas y metafísicas que impiden la felicidad de los hombres y propician la codicia.
} 
cuencia, la eliminación de las uolnera uitae (la herida de la vida): la avaricia y la ambición originadas por la inseguridad del individuo.

El éxito epicúreo fue lograr que el hombre dejara de mirar la muerte con miedo; que se alzara orgulloso ante la nada. Así, se suele decir, nada terrible hay en el vivir para quien nada terrible hay en el morir. La felicidad del epicúreo consiste en la dicha continua y no en objetivos lejanos que la muerte bruscamente pudiera arrebatarnos, dejando así una vida sin sentido. Por eso, la meditación acerca de nuestra mortalidad debe llevarnos a apreciar más y mejor el tiempo que tenemos a nuestro alcance. 